\title{
Structural and Contextual Dimensions of Iranian Primary Health Care System at Local Level
}

\author{
Mehdi Zanganeh Baygi ${ }^{1}$; Hesam Seyedin ${ }^{1,{ }^{*}}$; Masoud Salehi ${ }^{2}$; Mehdi Jafari Sirizi ${ }^{3}$ \\ 1 International Campus, Iran University of Medical Sciences, Tehran, IR Iran \\ ${ }^{2}$ Department of Biostatistics, Faculty of Public Health, Iran University of Medical Sciences, Tehran, IR Iran \\ ${ }^{3}$ Health Management and Economics Research Centre, School of Health Management and Information Sciences, Iran University of Medical Sciences, Tehran, IR Iran \\ *Corresponding Author: Hesam Seyedin, International Campus, Iran University of Medical Sciences, Tehran, IR Iran. Tel: +98-2188772088, E-mail: h.seyedin@iums.ac.ir
}

Received: January 3, 2014; Revised: February 3, 2014; Accepted: February 23, 2014

\begin{abstract}
Background: In recent years, family physician plan was established as the main strategy of health system in Iran, while organizational structure of the primary health care system has remained the same as thirty years ago.

Objectives: This study was performed to illustrate structural and contextual dimensions of organizational structure and relationship between them in Iranian primary health care system at local level.

Materials and Methods: A cross-sectional quantitative study was conducted from January to June 2013, during which 121 questionnaires were distributed among senior and junior managers of city health centers at Medical Sciences universities in Iran. Validity of the questionnaire was confirmed by experts $(\mathrm{CVI}=0.089$ and CVR more than 0.85$)$ and Cronbach $\alpha$ was utilized for reliability $(\alpha=0.904)$. We used multistage sampling method in this study and analysis of the data was performed by SPSS software using different tests.

Results: Local level of primary health care system in Iran had mechanical structure, but in contextual dimensions the results showed different types. There was a significant relationship between structural and contextual dimensions $(r=0.642$, P value $<0.001)$. Goals and culture dimensions had strongest effects on structural dimensions.

Conclusions: Because of the changes in goals and strategies of Iranian health system in recent years, it is urgently recommended to reform the current structure to increase efficiency and effectiveness of the system.
\end{abstract}

Keywords:Health Services Administration; Organizational Structure; Organizational Culture; Primary Health Care; Iran

\section{Background}

Health is a valuable asset, which paves the way for the development of personal capabilities as well as steady development of the society. Promoting health is not only a responsibility but also a right and as mentioned by the Iranian constitution, the government must provide health care to population on an equitable basis (1). Iran has signed the Alma-Ata Declaration in 1978, aiming health for all by the year 2000 using the primary health care (PHC) strategy (2). Moving in this direction, policymakers in Iran decided to enact and enforce the laws to reach the goal (3). To this effect, considerable changes were made in organizational structure of the health system. In 1985, at national level, medical education was merged with the health system duties and the Ministry of Health and Medical Education (MOHME) was developed (4). MOHME is responsible for all aspects of planning, leadership, supervision, and evaluation of health services in the country, including training of human resources for health at all levels (1). Moreover, at regional level, Medical Sciences universities were founded. Universities function independently but under the general rules and policies of MOHME (1).

In addition, health networks (HN) at local level are the most natural administrative level promoted by WHO for health delivery (5). The networks comprise City Health Centers (CHCs) and City hospitals. Also, at first level, Urban and Rural Health Centers (UHC and RHC) were formed to affect health status. At this level, Health houses in villages and Health posts in cities deliver health services (Figure 1) (5).

This structure had enormous efficiency in its first two

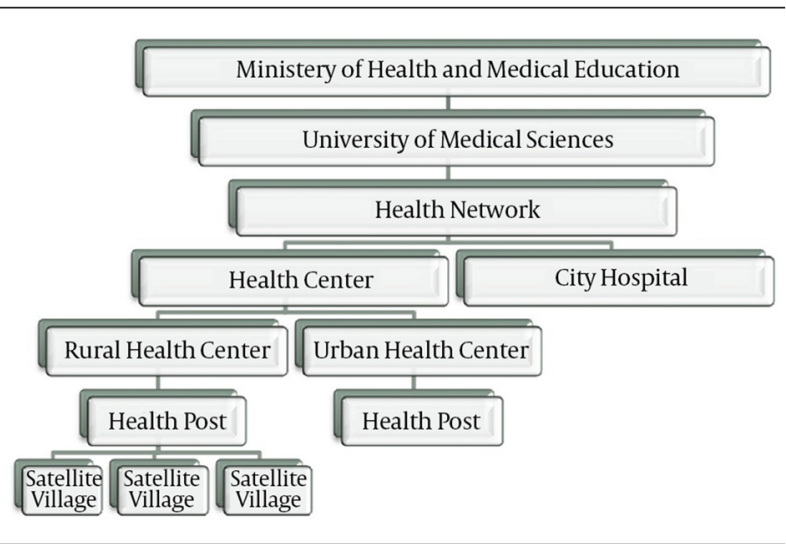

Figure 1. Organizational Structure of the Health System in Iran

Copyright (C) 2015, Iranian Red Crescent Medical Journal. This is an open-access article distributed under the terms of the Creative Commons Attribution-NonCommercial 4.0 International License (http://creativecommons.org/licenses/by-nc/4.0/) which permits copy and redistribute the material just in noncommercial usages, provided the original work is properly cited. 
decades of its operation $(1,3,5,6)$, as WHO reported in 2008: "the Islamic Republic of Iran's progressive roll-out of rural coverage is an impressive example of this model" (7).

In recent years, the MOHME implemented family physician and referral system plan as the main strategy in all rural areas and some cities (8). Despite the reforms, organizational structure of PHC system has not changed over the last thirty years (2). Organizational structure reform is required to have appropriate performance regarding new goals and strategies (9). A systematic review showed an imbalance between organizational structure and goals and strategies in Iran PHC system in 2013 (10). Also, the World Bank (WB) report stated that the current Iranian health system is inappropriate (11). Because an appropriate structure should be specified for reforms (12) and there was not any research about organizational structure of the system, this study aimed to illustrate the current organizational structure of PHC system at local level to help policymakers to better understand the weaknesses and strengths of the current system.

It is organizational structure that determines, organizes, and coordinates all organizational activities (9). Organizations design specific structures to perform their activities, increase coordination, and control their employees (13). Conformity of organizational structure with goals and strategies increases efficiency and effectiveness (14). Moreover, studies show that appropriate organizational structure promotes productivity, performance, and innovation (15-17).

Daft has divided Organizational structure into two dimensions: structural and contextual (13). Structural dimensions, which represent internal characteristics of organizations include formalization, complexity, centralization, specialization, standardization, hierarchy of authority, professionalism, and personnel ratios. These dimensions create a basis for measuring and comparing organizations. On the other hand, contextual dimensions are composed of goals, strategies, environment, culture, size, and technology. They describe organizational settings that influence and shape the structural dimensions (13). Table 1 shows the classification of contextual dimensions used in this study (18). Based on structural conditions, organizations are divided into organic and mechanical structures. Organic organizations have low formalization, complexity, and centralization, but mechanical organizations are quite the opposite (9).

In a study about organizational structure of Eastern Azerbaijan governorship in Iran, the structure was identified as mechanical with high formalization, complexity and centralization (19). In another study in 2013, organizational structure of Iranian Azad University was found mechanical with low complexity (17). High centralization in Iranian health system was mentioned in some studies $(2,20,21)$. On the other hand, in a qualitative study about organizational structure of psychosocial care centers in Brazil, low formalization and specialization, high pro- fessionalism, and decentralized decision making were detected as a result of team working (22). Significant relationship between contextual and structural dimensions was shown in a study about organizational structure of Iranian universities in 2004. In this research, except environment, all other contextual dimensions affect structural dimensions (23).

\begin{tabular}{lr}
\hline \begin{tabular}{l} 
Table 1. Classification of Contextual Dimensions in This Study \\
\hline $\begin{array}{l}\text { Contextual dimen- } \\
\text { sions }\end{array}$
\end{tabular} & Classification \\
\hline $\begin{array}{l}\text { Goals and strategies } \\
\text { Environment }\end{array}$ & $\begin{array}{r}\text { well-defined goals-goals not defined } \\
\text { unstable environment-stable environ- } \\
\text { ment }\end{array}$ \\
$\begin{array}{l}\text { Organizational } \\
\text { culture }\end{array}$ & $\begin{array}{r}\text { clear norms and values-ambiguous } \\
\text { norms and values }\end{array}$ \\
$\begin{array}{l}\text { Technology } \\
\text { Size }\end{array}$ & $\begin{array}{r}\text { high effect of technology-low effect of } \\
\text { technology }\end{array}$ \\
\hline
\end{tabular}

\section{Objectives}

In the present study, researchers attempted to detect and explain structural and contextual dimensions and relationship between them in organizational structure of Iranian PHC system at local level.

\section{Materials and Methods}

\subsection{Data collection}

A quantitative approach was adopted for this research. This cross-sectional study was conducted in Iran from January to June 2013 and data were collected at one time point from the sample organizations. A comprehensive questionnaire, which had used to detect organizational structure at Tehran University was utilized as an instrument to collect data (24). The questionnaire included demographic information and 88 questions, which were divided into 13 structural and contextual dimensions. Sixty questions cover 8 structural dimensions (formalization, complexity, centralization, specialization, standardization, hierarchy of authority, professionalism, and personnel ratios) and 28 other questions examine 5 contextual dimensions (goals and strategies, environment, culture, size, and technology). Five-level Likert scale was used to rate the answers; the choices of them were, "strongly agree," “agree," "I do not know," “disagree,” and "strongly disagree," which scored from 5 to 1 . Score of each dimension was calculated by adding scores of each item.

In order to ensure asking the right questions and avoiding ambiguity, a pilot study was performed to test the validity and reliability of the questionnaire, and amendments were made to the questionnaire as a result of the pilot study. To test the validity, the questionnaire was sent to 20 specialists of organizational structure, and their 
views were considered $(\mathrm{CVI}=0.089$ and CVR more than $0.85)$. In addition, to examine the internal consistency of the questionnaire, it was sent to $25 \mathrm{CHC}$ managers, from them, 23 questionnaires were returned. The Cronbach $\alpha$ was 0.904 , which shows a significant reliability for the questionnaire.

\subsection{Sampling; Universities Clustering}

Because of the various Medical Science universities in Iran, it was inapplicable to distribute the instrument in all universities. Therefore, universities were classified by K-Means Clustering method using seven important health indicators, which have been selected by health experts. They included infant mortality rate, under-one mortality rate, under-five mortality rate, low birth weight rate, delivery at home by unskilled attendants, crude birth rate, and population growth rate (25). Indicators have extracted from vital horoscope annually (26). Universities were classified in 3 clusters: good, intermediate, and weak.

By multistage sampling method, one university from every cluster was selected randomly: Shahid Beheshti, Sari, and Zahedan. Then, cities of these universities were classified into three clusters (good, intermediate, and weak) based on the same indicators. Because of the time and cost limitations, one city was selected from each cluster. At the end, 9 cities were selected randomly from 3 universities: Shahriar, Robat Karim, and Firuzkuh from Shahid Beheshti University, Galugah, Behshahr, and Neka from Sari University, and finally Zahedan, Konarak, and Iranshahr from Zahedan University.

All $121 \mathrm{CHC}$ senior and junior managers in these health centers were selected as respondents. There were no inclusion or exclusion criteria for the study. Researchers hold a meeting to explain the study in each city for respondents. Then, the questionnaires were completed by them. Ethical issues such as voluntary participation, con- fidentiality, and anonymity were considered in the study.

\subsection{Data Analysis}

The data were entered into SPSS software and after its clearance, the whole dataset was analyzed. After consulting a statistician and relevant literature to analyze the data, it was decided to assign a scale from 1 to 5 (from "completely disagree" to "completely agree"). Frequency tables, mean, standard deviation, and variance were used to describe the data and Shapiro-Wilk test, independent samples t test, 1-way analysis of variance (ANOVA), correlation coefficients (Pearson and Spearman), and multiple linear regression analysis were utilized for data analysis. Also, the normality assumption, independency and homogeneity of variances assumption were checked for $t$ test and ANOVA tests.

\section{Results}

\subsection{Demographic Information}

Nine senior and 112 junior managers (52 men and 69 women) completed the questionnaire. The average age of respondents was 35.8 ( \pm 6.6 ) years and their work record average was 12 ( \pm 7.1$)$ years. Eighty-one percent of the respondents had bachelor's or master's degree and 19\% were physician.

\subsection{Current Condition of Structural Dimensions}

Based on the number of items in each dimension of the questionnaire, score range, upper range, and lower range were scaled. By calculating the scores, authors determined the level of structural dimensions in the current condition. Table 2 showed that local level of PHC system in Iran had high position in all dimensions except professionalism. On the whole, the structural dimensions of the system were mechanical.

Table 2. Iranian PHC System at Local level: Current Condition Level of Structural Dimensions a

\begin{tabular}{|c|c|c|c|c|c|c|c|}
\hline Dimension & $\begin{array}{c}\text { Items } \\
\text { Number }\end{array}$ & $\begin{array}{l}\text { Score } \\
\text { Range }\end{array}$ & $\begin{array}{l}\text { Lower } \\
\text { Range }\end{array}$ & $\begin{array}{l}\text { Upper } \\
\text { Range }\end{array}$ & Raw Score & Transformed Score, \% & $\begin{array}{c}\text { Current Condition } \\
\text { Level }\end{array}$ \\
\hline Formalization & 12 & $12-60$ & $12-36$ & $37-60$ & $41.2 \pm 7.1$ & 68.6 & High $^{b}$ \\
\hline Complexity & 6 & $6-30$ & $6-18$ & $19-30$ & $18.8 \pm 3.4$ & 62.6 & High $\mathrm{b}$ \\
\hline Centralization & 14 & $14-70$ & $14-42$ & $43-70$ & $43 \pm 7.9$ & 61.4 & High $^{b}$ \\
\hline Specialization & 4 & $4-20$ & $4-12$ & $13-20$ & $14.4 \pm 2.9$ & 72 & High b \\
\hline Standardization & 4 & $4-20$ & $4-12$ & $13-20$ & $13.6 \pm 2.7$ & 68 & High b \\
\hline Hierarchy & 10 & $10-50$ & $10-30$ & $31-50$ & $32.7 \pm 5.9$ & 65.4 & High $^{b}$ \\
\hline Professionalism & 6 & $6-30$ & $6-18$ & $19-30$ & $16.7 \pm 4.8$ & 55.6 & Low $^{\mathrm{C}}$ \\
\hline Personnel ratio & 4 & $4-20$ & $4-12$ & $13-20$ & $13.2 \pm 3$ & 66 & High $\mathrm{b}$ \\
\hline Total & 60 & $60-300$ & $60-180$ & $181-300$ & $193.9 \pm 20.5$ & 64.6 & Mechanical $^{\mathrm{b}}$ \\
\hline
\end{tabular}


Zanganeh Baygi M et al.

\begin{tabular}{|c|c|c|c|c|c|c|c|}
\hline Dimension & $\begin{array}{l}\text { Items } \\
\text { Number }\end{array}$ & $\begin{array}{l}\text { Score } \\
\text { Range }\end{array}$ & $\begin{array}{l}\text { Lower } \\
\text { Range }\end{array}$ & $\begin{array}{l}\text { Upper } \\
\text { Range }\end{array}$ & $\begin{array}{l}\text { Raw Score; } \\
\text { Mean } \pm \text { SD }\end{array}$ & $\begin{array}{c}\text { Transformed } \\
\text { Score; } \%\end{array}$ & Current Condition Level \\
\hline Goals & 8 & $8-40$ & $8-24$ & $25-40$ & $26.4 \pm 5.2$ & 66 & Well-defined $^{\mathrm{a}}$ \\
\hline Environment & 9 & $9-45$ & $9-27$ & $28-45$ & $31.9 \pm 4.7$ & 70.8 & Dynamic $^{\mathrm{a}}$ \\
\hline Culture & 4 & $4-20$ & $4-12$ & $13-20$ & $11.6 \pm 3.3$ & 58 & Ambiguous norms and values $b$ \\
\hline Technology & 4 & $4-20$ & $4-12$ & $13-20$ & $13.5 \pm 3.5$ & 67.5 & High effect ${ }^{a}$ \\
\hline Size & 3 & 3-15 & $3-9$ & $10-15$ & $7.7 \pm 2.4$ & 51.3 & Small ${ }^{b}$ \\
\hline Total & 28 & $28-140$ & $28-84$ & $85-140$ & $91.2 \pm 14.3$ & 65.1 & Proper ${ }^{a}$ \\
\hline
\end{tabular}

\subsection{Current Condition of Contextual Dimensions}

Scaling method of these dimensions was similar to the structural dimensions; however, in this part, the current condition had been determined according to Table 1. Results indicated that the local level of PHC system in Iran had well-defined goals and strategies, dynamic environment, ambiguous norms and values, and small size. Also, technology had strong effect on the system. Totally, the contextual dimensions of the system were proper (Table 3).

\subsection{Comparison of the Results Among Different Universities and Different Posts}

By using Schapiro-Wilk test to check the normality of total structural dimensions, it was found that the dimensions in different universities and posts were distributed normally $(\mathrm{P}>0.05)$. Next, 1-way ANOVA test showed that there was no statistical difference among the mean of total structural dimensions in three universities $(\mathrm{P}=0.055)$. Also, based on independent samples t test, there was no statistical difference among two groups of respondents: CHC senior and junior managers $(\mathrm{P}=0.894)$.

\subsection{Relationship Between Contextual and Struc- tural Dimensions}

Shapiro-Wilk test showed that contextual dimensions were not distributed normally $(\mathrm{P}<0.05)$. Therefore, Spearman correlation coefficient test was used. Results showed that all of the structural dimensions had significant relationship with contextual dimensions in the current condition $(\mathrm{P}<0.001)$. Centralization dimension had an inverse relationship with the contextual dimensions, however, the other structural dimensions had direct relationships (Table 4).

\subsection{Prediction of Most Important Contextual Di- mensions Which Effect on Total Structural Dimen- sions}

Correlation coefficient only shows the bivariate relationship between different variables, but regression analysis considers the relationship of the independent variables on dependent variable simultaneously. Multiple linear regression analysis, after checking its assumptions, showed that environment and size dimensions had no effects on total structural dimensions. Therefore, after removing insignificant dimensions in the final model (Table 5), the goals dimension had the strongest effect on the total structural dimensions, and the culture and technology dimension were in the second and third rank, respectively $(\mathrm{P}<0.05)$.

Table 4. Correlation Coefficients Between Contextual and Structural Dimensions in Iranian PHC System at Local Level

\begin{tabular}{lcc}
\hline Dimension & $\begin{array}{c}\text { Spearman Correlation } \\
\text { Coefficient }\end{array}$ & PValue $^{\mathrm{a}}$ \\
\hline Formalization & 0.523 & $<0.001$ \\
Complexity & 0.385 & $<0.001$ \\
Centralization & -0.562 & $<0.001$ \\
Specialization & 0.443 & $<0.001$ \\
Standardization & 0.504 & $<0.001$ \\
Hierarchy & 0.684 & $<0.001$ \\
Professionalism & 0.617 & $<0.001$ \\
Personnel ratio & 0.482 & $<0.001$ \\
Total structural & 0.642 & $<0.001$ \\
dimensions & & \\
\hline
\end{tabular}

a Significant level $\alpha=0.05$

Table 5. Final Model of Linear Regression Analysis Between Contextual and Structural Dimensions in Iranian PHC System at Local Level $^{\mathrm{a}}$

\begin{tabular}{lcccc}
\hline Dimension & Est & SE & SdE & PValue $^{\text {b }}$ \\
\hline Goals & 1.605 & 0.329 & 0.407 & $<0.001$ \\
Culture & 1.343 & 0.483 & 0.221 & 0.006 \\
Technology & 1.123 & 0.476 & 0.195 & 0.020 \\
\hline $\begin{array}{l}\text { a abbreviations: Est, Estimate; SE, Standard Error; SdE, Standardized } \\
\text { Estimate. } \\
\text { b Significant level } \alpha=0.05 .\end{array}$ & & &
\end{tabular}




\section{Discussion}

Based on literature review, most of the published articles about Iran's health system are about target achievements and outcomes. For instance, a supplementary issue of Iranian Journal of Public Health in 2009 titled: Iran's achievements in health, three decades after the Islamic revolution (27). There was only a systematic review similar to this research carried out in 2013. The authors concluded that: "because of the fundamental changes in goals and strategies, reforms in the organizational structure of PHC system in Iran, especially in peripheral levels are highly recommended" (10). Also, this study can have useful results in this regard.

This study showed that organizational structure at local level of PHC system in Iran is mechanical. All structural dimensions except professionalism are located at high level. The reason for the low level of professionalism is the need for skillful employees, which has been neglected. Similar to the present findings, mechanical structure with high formalization, complexity, and centralization was identified in organizational structure of Eastern Azerbaijan governorship in Iran in 2012 (19). Also, the organizational structure of Iranian Azad University was mechanical with low complexity (17). These studies showed that organic structure has been neglected in these organizations despite recommendations of modern management models $(9,18)$.

High level of formalization, standardization, and specialization at this level might be due to diversity of activities, procedures, and jobs such as supervising family health, disease control, and environmental health activities of lower level, which are performed in the system (6). A similar study in 2008 showed that organizational structure at Chinese universities was mechanical with high formalization, standardization, and specialization (28). Contrary to these results, in a qualitative study about organizational structure of psychosocial care centers in Brazil, low formalization and specialization, high professionalism, and decentralized decision making were detected as a result of team working (22).

High centralization in the local level of PHC system in Iran is shown in the current study. Most previous researches in Iranian health system in different units support this issue $(2,20,21)$. Moreover, WB report confirmed high centralization in PHC structure of Iran (11). Despite the formation of boards of trustees in all universities in Iran, decision making has not been decentralized properly, which requires consideration (29). Similar to Iran, PHC system in Thailand was over centralized based on a qualitative study in 2013 (30). In this regard, WHO and WB recommended governments, especially in developing countries to decentralize their health systems (31). Of course, this procedure has different effects in various countries. In a study, success of decentralization with proper outcomes was identified in four countries. For example, it concluded with proper outcomes in treatment of the patients in Malawi (32); however, decentralization on health financing and governance policies in Mexico produced both positive and negative effects (33).

In this study, ambiguous norms and values in organizational culture of the system were significant considering the findings of contextual dimensions. As it was said: "Organizations whose cultures do not tolerate ambiguity, are closed to admitting mistakes, punish mistakes, and fall into the mechanistic category from the organizational cultural viewpoint" (34). Scott and collogues believed that: "Managing organizational culture is increasingly viewed as an essential part of the health system reform". Moreover, they stated that: "yet planned culture change is a difficult, uncertain and risky enterprise" (35). Hence, to reach a better situation such as learning organizations or motivation in the work context, more attention should paid to this issue (36).

In view of other contextual dimensions, well defined goals and strategies, dynamic environment, small size, and high effect of technology on Iranian PHC system at the local level, the findings of Brodar study about organizational structure of public sector in Varazdin county in Croatia were similar to this research (37). Also, in psychosocial care centers in Brazil, contextual dimensions such as complex environment, and small size were similar to our findings, however, regarding technology dimension, their results were different (22). The authors believed that: "low formalization level seems to be ideal for a small organization" but, in Iranian PHC system there is high formalization.

Significant relationship and effects of contextual dimensions on structural dimensions in this research were consistent with other studies $(9,18)$. Similar to the present findings, Farhanghi et al. believed that information technology affects structural dimensions and leads to high performance (38). In a study about organizational structure of Iranian universities, all contextual dimensions except environment affected structural dimensions (23). Another similarity with this study was that there was no difference between structures at universities. On the other hand, in that study technology had the most influence among contextual dimensions, despite the highest effects of goals and strategy in the present research (23).

Now, Iran is on the verge of running family physician and referral system plan as the most important reform in the health sector (8). Based on the present findings, decentralization is one of the main processes, which should be considered in the system. Majority of rules, programs, and guidelines are needed to be revised to reduce the formalization. High level of complexity leads system to be more fragmented and bureaucratic, which should be reformed based on new goals and strategies. As a result of these reforms, the system will be more organic. In this regard, paying attention to contextual dimensions, especially organizational culture can accelerate these processes. Upstream policies such as Iran fifth five-Year Development Plan and Iran's Health Map emphasize “im- 
plementing universal and comprehensive health care system based on PHC system" and "modifying the organizational structure of health services network in order to meet priorities and basic needs" (39). Finally, it is clear that without appropriate adjustment between goals and strategies with organizational structure in PHC system, policymakers cannot successfully conduct their plans.

Difficulty of access to some important managers in different cities during the study and variety of items in the questionnaire limited our research. In this regard, authors arranged with respondents before going to the cities and hold the meeting to explain the concepts. Selection of different levels of universities and participants were strengths of this study; however, small sample size (because of time and cost limitation) was weakness of the study.

\section{Acknowledgements}

Our thanks go to the personnel and managers of city health centers for their support and help.

\section{Authors' Contributions}

Designing the method of study; collection, validation, and analysis of the data; drafting the manuscript, and final revision: Mehdi Zanganeh Baygi and Heasm Seyedin. Validation and analysis of the data and final revision: Masoud Salehi and Mehdi Jafari Sirizi.

\section{References}

1. Sadrizadeh B. Health situation and trend in the Islamic Republic of Iran. Iranian J Publ Health. 2001;30(1-2):1-8.

2. Moghadam MN, Sadeghi V, Parva S. Weaknesses and challenges of primary healthcare system in Iran: a review. Int J Health Plann Manage. 2012;27(2):e121-31.

3. Shadpour K. Primary health care networks in the Islamic Republic of Iran. East Mediterr Health J. 2000;6:822-5.

4. Marandi SA. The integration of medical education and health care services in the IR of Iran and its health impacts. Iranian JPubl Health. 2009;38(Suppl.1):4-12.

5. Sadrizadeh B. Primary health care experience in Iran. Iran Red Crescent Med J. 2004;7(1):79-90.

6. Aghajanian A, Mehryar AH, Ahmadnia S, Kazemipour S. Impact of rural health development programme in the Islamic Republic of Iran on rural-urban disparities in health indicators. East Mediterr Health J. 2006;13(6):1466-75.

7. World Health Organization, van Lerberghe W. The World Health Report 2008: Primary Health Care : Now More Than Ever: World Health Organization; 2008.

8. Majdzadeh R. Family physician implementation and preventive medicine; opportunities and challenges. Int J Prev Med. 2012;3(10):665-9.

9. Robbins SP. Organization Theory: Structure, Design, and Applications.: Prentice Hall;1990.

10. Zanganeh Baygi M, Seyedin H. Imbalance between Goals and Organizational Structure in Primary Health Care in Iran- a Systematic Review. Iran J Public Health. 2013;42(7):665-72.

11. Gressani D, Saba J, Fetini H, Rutkowski M, Maeda A, Langenbrunner J. Islamic Republic of Iran health sector review, volume I: main report. The World Bank Group. Human Development Sector, Middle East and North Africa. 2007:1575-81.

12. Shadpour K. Health sector reform in Islamic Republic of Iran. Hakim Res J. 2006;9(3):1-18.

13. Daft RL. Essentials of Organization Theory and Design.: South-West- ern College Publishing; 1998.

14. Zheng W, Yang B, McLean GN. Linking organizational culture, structure, strategy, and organizational effectiveness: Mediating role of knowledge management. J Bus Res. 2010;63(7):763-71.

15. Damanpour F, Gopalakrishnan S. Theories of organizational structure and innovation adoption: the role of environmental change. J Eng Technol Manage. 1998;15(1):1-24.

16. Pertusa-Ortega EM, Zaragoza-Sáez P, Claver-Cortés E. Can formalization, complexity, and centralization influence knowledge performance? J Bus Res. 2010;63(3):310-20.

17. Chegini MG, Yousefi S, Rastad S. Competitive Study of Effects about Dimensions of Organizational Structure on Productivity J Basic Appl Scie Res. 2013;3(4):318-26.

18. Daft R. Organization Theory and Design.: Cengage Learning; 2006.

19. Vazifedoust H, Nasiri M, Norouzi A. Analyzing the relationship between organizational structure and employee empowerment in Eastern Azerbaijan. Interdiscip J Res Business. 2012;2(6):10-24.

20. Jafari M, Rashidian A, Abolhasani F, Mohammad K, Yazdani S, Parkerton P, et al. Space or no space for managing public hospitals; a qualitative study of hospital autonomy in Iran. Int J Health Plan M. 2011;26(3):e121-37.

21. Sirizi MJ, Fiezabadi VY, Aleksanyan AS. Major Policies in Health Area in Islamic Republic of Iran During Past 30 Years: Results, Challenges and Strategies. Res J Biol Sci. 2010;5(10):683-91.

22. Ventura CAA, Araujo AS, Moll MF. Organizational dimensions of a Psychosocial Care Center for chemical dependency. Acta Paul Enferm. 2011;24(5):650-5.

23. Arabi SM, Kaboli. M.R. . Effect of technology, size, environment and decision maker viewpoints on organizational structure. In dustrial Management. 2004;4:21-39.

24. Ziaee MS. Need to review and redesign the organizational structure of educational and research institutions. Management $\mathrm{Cul}$ ture. 2003;1(4):111-37.

25. Movahedi M, Hajarizadeh B, Rahimi A, Arshinchi M, Amirhosseini K, Haghdoost AA. Trends and geographical inequalities of the main health indicators for rural Iran. Health Policy Plan. 2009;24(3):229-37.

26. Khosravi A, Motlagh ME, Emami Razavi SH. The Iranian vital horoscope; appropriate tool to collect health statistics in rural areas. Iranian J Publ Health. 2009;38(1):74-80.

27. Khosravi A, Motlagh ME, Emami Razavi SH. Expanded Programme on Immunization in Iran: Last 3 Decades Achievements from 1979 to 2008. Iranian Journal of Public Health. 2009;38(Suppl. $1): 81$.

28. Xiong Y, LIU Z. Analysis on Resource-based View of Organizational Innovation of Colleges and Universities in China. New Century Talents Support Plan. 2008:136-45.

29. Damari B, Aminloo H, Farzan H, Rahbari M, Alikhani S. Ways to improve the current performance of the boards of trustees of medical universities in iran. Iran J Public Health. 2013;42(Supple1):36-41.

30. Tejativaddhana P, Briggs D, Fraser J, Minichiello V, Cruickshank M. Identifying challenges and barriers in the delivery of primary healthcare at the district level: a study in one Thai province. Int J Health Plann Manage. 2013;28(1):16-34.

31. Bossert TJ, Beauvais JC. Decentralization of health systems in Ghana, Zambia, Uganda and the Philippines: a comparative analysis of decision space. Health Policy Plan. 2002;17(1):14-31.

32. Chan AK, Mateyu G, Jahn A, Schouten E, Arora P, Mlotha W, et al Outcome assessment of decentralization of antiretroviral therapy provision in a rural district of Malawi using an integrated primary care model. Trop Med Int Health. 2010;15(s1):90-7.

33. Arredondo A, Orozco E. Effects of health decentralization, financing and governance in Mexico. Rev Saude Publica. 2006;40(1):15260.

34. In: Bangert D, Doktor D editors. The role of organizational culture in the management of clinical e-health systems. Proceedings of the 36th Hawaii international conference on system sciences. 2003 p. 2 .

35. Scott TIM, Mannion R, Davies HTO, Marshall MN. Implementing culture change in health care: theory and practice. Int J Quality Health Care. 2003;15(2):111-8.

36. Franco LM, Bennett S, Kanfer R. Health sector reform and public 


\section{Zanganeh Baygi M et al.}

sector health worker motivation: a conceptual framework. Soc Sci Med. 2002;54(8):1255-66.

37. Brodar K, Klacmer Calopa M, Pihir I. Impact of ICT on the structural and contextual organizational elements: Case of the Varaždin County. J Info Org Sci. 2009;33(2):243-54.

38. Farhanghi AA, Abbaspour A, Ghassemi RA. Examining the Structural Relationships of New Communication and Information
Technologies, Organizational Structure and Firm Performance: An Analysis of Consultant Engineers Firms (CEF) in Iran. World App Sci J. 2012;20(4):605-14.

39. Vosoogh Moghaddam A, Damari B, Alikhani S, Salarianzedeh M, Rostamigooran N, Delavari A, et al. Health in the 5th 5-years Development Plan of Iran: Main Challenges, General Policies and Strategies. Iran J Public Health. 2013;42(Supple1):42-9. 